\title{
Bacteriological profile and antibiotic susceptibility of neonatal sepsis in neonatal intensive care unit of a tertiary hospital in Nepal
}

Bhishma Pokhrel ${ }^{1 *}$ (D), Tapendra Koirala ${ }^{2}$, Ganesh Shah ${ }^{1}$, Suchita Joshi ${ }^{1}$ and Pinky Baral ${ }^{3}$

\begin{abstract}
Background: Neonatal sepsis, one of the leading causes of mortality in neonatal intensive care units (NICU) of developing countries like Nepal, is often not extensively studied. In order to decrease the morbidity and mortality associated with neonatal sepsis, neonatologists should have a keen knowledge of the existing bacteriological flora and their antibiotic susceptibility pattern. In this study, we aim to determine the bacteriological profile and antibiotic susceptibility pattern of culture positive neonatal sepsis in the NICU of a tertiary teaching hospital in Nepal.
\end{abstract}

Methods: This was a retrospective cross-sectional study of all blood culture positive sepsis cases among neonates admitted to the neonatal intensive care unit of Patan Hospital, Nepal between April 15, 2014 and April 15, 2017. All neonates with a clinical suspicion of sepsis with a positive blood culture were identified. Patient demographics, clinical details, maternal risk factors, and laboratory data including bacteriological profiles and antimicrobial susceptibilities were recorded and analyzed.

Results: Of the 336 neonates admitted in the NICU, 69 (20.5\%) had culture-positive sepsis. The majority were early-onset sepsis $(n=54,78.3 \%)$ and were among the preterm babies ( $n=47,68.1 \%)$. Most bacterial isolates were gram-negative, predominantly the Klebsiella species $(n=23,33.3 \%)$. Klebsiella showed high resistance to commonly used antibiotics such as; Cefotaxime (90.5\%), Gentamicin (75\%), Ciprofloxacin (76.2\%), Ofloxacin (72.2\%) and Chloramphenicol (65\%). However, they showed good susceptibility to Carbapenems (100\%), Colistin (88.8\%) and Tigecycline (81.8\%). Among cultures with gram-positive species, Coagulasenegative Staphylococci (CONS) $(n=14,20.3 \%)$ predominated. CONS showed high resistance to Oxacillin (80\%), Cefotaxime (66.7\%) and Meropenem (80\%) but good susceptibility (100\%) to Vancomycin and Linezolid. Prevalence of multidrug-resistant strain was $73.9 \%$.

Conclusions: Klebsiella species and CONS were the most common causes of neonatal sepsis in our study. A significant proportion of the isolates were multidrug resistant strains, which pose a great threat to neonatal survival, and thereby, warrant modification of existing empirical therapy. Implementation of effective preventive strategies to combat the emergence of antibiotic resistance is urgently needed. We recommend a combination of Piperacillin-Tazobactam and Ofloxacin as the first line therapy and combination of Vancomycin and Meropenem as the second line empirical therapy in our NICU.

Keywords: Antibiotic susceptibility, Klebsiella, Multi-drug resistance, Neonatal sepsis, NICU

\footnotetext{
* Correspondence: bhishmapokhrel@pahs.edu.np

'Department of Pediatrics, Patan Academy of Health Sciences, Lagankhel, PO

Box 26500, Lalitpur, Nepal

Full list of author information is available at the end of the article
}

(c) The Author(s). 2018 Open Access This article is distributed under the terms of the Creative Commons Attribution 4.0 International License (http://creativecommons.org/licenses/by/4.0/), which permits unrestricted use, distribution, and reproduction in any medium, provided you give appropriate credit to the original author(s) and the source, provide a link to the Creative Commons license, and indicate if changes were made. The Creative Commons Public Domain Dedication waiver (http://creativecommons.org/publicdomain/zero/1.0/) applies to the data made available in this article, unless otherwise stated. 


\section{Background}

Sepsis is considered one of the leading causes of neonatal mortality globally, more so in developing countries like Nepal [1]. According to Nepal Demographic and Health Survey 2016, national neonatal mortality rate was 21 per thousand live births. Infections including sepsis contributed to $16 \%$ of the neonatal mortality [2]. Emergence of antimicrobial resistance has become a global concern. With a limited reserve of antibiotics, increasing antimicrobial resistance has become a great challenge in the management of neonatal sepsis. Knowledge of prevalent bacterial isolates and their antibiotic susceptibility pattern is crucial when choosing the appropriate empirical therapy in order to decrease morbidity and mortality. There is, however, a paucity of such data in Neonatal Intensive Care Units (NICU) of Nepal. We aim to determine the prevalence of culture-positive neonatal sepsis, its clinico-bacteriological profile and antibiotic susceptibility pattern in the NICU of Patan Hospital, Lalitpur, Nepal.

\section{Methods}

This was a retrospective cross-sectional study conducted in the NICU of Patan Hospital. Patan Hospital is the tertiary level teaching hospital of Patan Academy of Health Sciences (PAHS) located in Lalitpur, Nepal. It has a six-bed NICU, caring on average for 120 critically ill neonates annually. Neonates admitted to the NICU between April 15, 2014 and April 15, 2017 with clinical features of sepsis and who had a positive blood culture were included in the study. Blood cultures were sent in neonates with either a clinical suspicion of sepsis or risk factors for it. Sepsis was suspected in the presence of temperature instability, lethargy, feeding intolerance, respiratory distress, hemodynamic instability, convulsion, hypotonia, irritability or bleeding diathesis. Prematurity ( $<37$ weeks of gestation), low birth weight $(<2500 \mathrm{~g})$, history of resuscitation at birth, rupture of membrane for more than $18 \mathrm{~h}$ (PROM), antepartum fever, foul-smelling liquor and repeated $(\geq 3)$ unclean per vaginal examinations were considered as risk factors for neonatal sepsis.

Patan Hospital follows standard microbiological techniques. Before drawing blood, the skin is disinfected with $10 \%$ Povidone-iodine solution for $2 \mathrm{~min}$, followed by $0.5 \%$ Chlorhexidine solution for 1 minute. One to three milliliters of blood is taken aseptically from a peripheral vein and injected into the BACTEC PedsPlus ${ }^{\mathrm{Tm}}$ (Becton Dickinson, Ireland) culture vials. It is then incubated in an automated BACTEC system at $35 \pm 2^{\circ}$ $\mathrm{C}$ for 5 days as per manufacturer's instructions. Subculture and organism identification is performed as described by Koneman et al. [3]. Antibiotic susceptibility test is done using the Kirby-Bauer disc diffusion method, as per the Clinical and Laboratory Standards Institute (CLSI) guidelines (2014) [4]. After collection of blood for culture, neonates are started on empiric intravenous Ampicillin and Amikacin (first line therapy). If there is no clinical response after 48-72 h, antibiotics are upgraded to intravenous Chloramphenicol and Ofloxacin (second line) or Meropenem and Colistin (third line). These are later modified, based on culture and antibiotic susceptibility results. Coagulase-negative Staphylococcus (CONS) isolated from non-septic neonates, in whom the repeat culture showed no growth, was considered as a contaminant and hence excluded from the study. Early-onset sepsis (EOS) was defined as sepsis occurring within first $72 \mathrm{~h}$ of life, that occurring after $72 \mathrm{~h}$ of life was defined as late-onset sepsis (LOS) [5]. Multidrug-resistant (MDR) strains were defined as per international standard definitions for acquired resistance and relative to the panel of antibiotics tested for each isolate, as in vitro non-susceptibility to $\geq 1$ agent in $\geq 3$ antimicrobial categories: Penicillins, Cephalosporins, Beta-lactamase inhibitor combinations, Fluoroquinolones, Aminoglycosides, Chloramphenicol, Folate pathway inhibitors, Tetracyclines, Macrolides and Glycopeptides [6].

For data collection, microbiology laboratory blood culture registers were reviewed and all blood culture positive neonates were identified. Their records were subsequently evaluated for clinical evidence of sepsis and enrolled in the study. Data on age at admission, gestational age at birth, birth weight, maternal risk factors, laboratory parameters, blood culture isolates and their susceptibility pattern and clinical outcome were collected. EpiInfo ${ }^{\text {тм }}$ for Mobile was used for data entry and Statistical Package for Social Sciences (SPSS) version 21 was used for data analysis. Summary of measures were reported as percentage for categorical variables and as mean with standard deviation for quantitative variables. Fisher's exact test was used to infer any differences between the categorical variables and $p$-value of less than 0.05 was considered statistically significant. Ethical approval to conduct the study was obtained from the Institutional Review Committee (IRC) of PAHS.

\section{Results}

\section{General characteristics and clinical profile}

During the study period, 24,516 live births occurred, and 336 neonates were admitted in our NICU of whom 332 had their blood sent for culture and susceptibility test. Out of 336 neonates, 69 (20.5\%) had culture-positive sepsis. EOS was found in $78.3 \%$. Among neonates with positive cultures, $63.8 \%$ had a birth weight less than $2500 \mathrm{~g}$, $68.1 \%$ were preterm and $27.5 \%$ were delivered by emergency cesarean section (Table 1 ). Forty-five percent had a maternal history of PROM, which was more common 
Table 1 General characteristics of the enrolled neonates

\begin{tabular}{|c|c|c|c|c|c|}
\hline Variables & EOS group & LOS group & Total & Percent & Fisher's exact test $p$-value \\
\hline \multicolumn{6}{|l|}{ Neonatal variables } \\
\hline \multicolumn{6}{|l|}{ Gender } \\
\hline Male & 31 & 6 & 37 & 53.6 & \multirow[t]{2}{*}{0.2571} \\
\hline Female & 23 & 9 & 32 & 46.4 & \\
\hline \multicolumn{6}{|l|}{ Gestational age at birth } \\
\hline Preterm (<37 weeks) & 42 & 5 & 47 & 68.1 & \multirow[t]{2}{*}{0.0033} \\
\hline Term (> 37 weeks) & 12 & 10 & 22 & 31.9 & \\
\hline \multicolumn{6}{|l|}{ Birthweight } \\
\hline$<2500 \mathrm{~g}$ & 34 & 10 & 44 & 63.8 & \multirow[t]{2}{*}{1.0000} \\
\hline$\geq 2500 \mathrm{~g}$ & 20 & 5 & 25 & 36.2 & \\
\hline \multicolumn{6}{|l|}{ Mode of delivery } \\
\hline Vaginal & 35 & 8 & 43 & 62.3 & \multirow[t]{2}{*}{0.5484} \\
\hline Caesarean section & 19 & 7 & 26 & 37.7 & \\
\hline APGAR score $<6$ at 5 min & 5 & 0 & 5 & 7.3 & 0.6250 \\
\hline \multicolumn{6}{|l|}{ Maternal variables } \\
\hline Maternal fever (within 7 days before delivery) & 9 & 0 & 9 & 13.0 & 0.0039 \\
\hline PROM of $>18 \mathrm{~h}$ & 29 & 2 & 31 & 44.9 & $<0.0001$ \\
\hline Foul smelling liquor & 2 & 0 & 2 & 2.9 & 0.5000 \\
\hline Maternal antibiotics (within 7 days before delivery) & 19 & 2 & 21 & 30.4 & 0.0002 \\
\hline Maternal GBS colonization & 12 & 0 & 12 & 17.4 & 0.0004 \\
\hline \multicolumn{6}{|l|}{ Neonatal care related variables } \\
\hline Need for inotropes & 39 & 2 & 41 & 59.4 & $<0.0001$ \\
\hline Need for positive pressure ventilation & 54 & 10 & 64 & 92.8 & $<0.0001$ \\
\hline Central line & 47 & 3 & 50 & 72.5 & $<0.0001$ \\
\hline Mortality & 11 & 0 & 11 & 15.9 & 0.0009 \\
\hline
\end{tabular}

EOS Early onset sepsis, GBS Group B Streptococcus, LOS Late onset sepsis, PROM Prolonged rupture of membrane

among the EOS group (54\%). Maternal Group B Streptococcus (GBS) colonization status was unknown in $69.6 \%$.

The common clinical findings observed at admission were respiratory distress (79.7\%), tachycardia (60.9\%), cyanosis $(59.4 \%)$ and hypothermia (53.6\%). Similarly, low absolute neutrophil count (ANC) $\left(<1800 / \mathrm{mm}^{3}\right)$, thrombocytopenia $\left(<150,000 / \mathrm{mm}^{3}\right)$ and raised C-reactive protein (CRP) $(>10 \mathrm{mg} / \mathrm{dl})$ were seen in 20,75 and $84 \%$ respectively. During the course of treatment, feeding intolerance, seizure, and dysglycemia (blood sugar level $<40$ $\mathrm{mg} / \mathrm{dl}$ requiring dextrose bolus or $>250 \mathrm{mg} / \mathrm{dl}$ requiring insulin infusion) was observed in 46.4, 31.9 and $27.5 \%$ respectively. The mean duration of NICU stay was $16.0 \pm 10.7$ days and the mortality rate was $15.9 \%$.

\section{Bacteriological profile}

The majority of bacterial isolates were gram-negative (77\%). Among the total isolates, Klebsiella species, CONS and Enterobacter were the most common (Table 2). Five cases (7.24\%) had polymicrobial sepsis of which two had yeast cells along with bacterial growth.
Table 2 Distribution of bacterial isolates with their relative frequency

\begin{tabular}{lll}
\hline Bacterial isolate & Number & Percent \\
\hline Gram-negatives & 23 & 33.3 \\
Klebsiella species & 13 & 18.8 \\
Enterobacter species & 8 & 11.6 \\
Acinetobacter species & 3 & 4.3 \\
Escherichia coli & 3 & 4.3 \\
Serratia rubidaea & 2 & 2.9 \\
Pseudomonas species & 1 & 1.4 \\
Bacillus species & & \\
Gram-positives & 14 & 20.3 \\
CONS & 1 & 1.4 \\
Staphylococcus aureus & 1 & 1.4 \\
Non-hemolytic streptococcus & 69 & 100.0 \\
Total &
\end{tabular}

CONS Coagulase negative staphylococci 
Table 3 Distribution of isolates based on age at admission and gestational age at birth

\begin{tabular}{|c|c|c|c|c|c|c|}
\hline \multirow[t]{2}{*}{ Bacterial isolate } & \multicolumn{3}{|c|}{ Age at admission } & \multicolumn{3}{|c|}{ Gestational age at birth } \\
\hline & $<72$ h (EOS) & $>72 \mathrm{~h}$ (LOS) & Fisher's exact test ( $p$-value) & Pre-term & Term & Fisher's exact test ( $p$-value) \\
\hline Klebsiella & 19 & 4 & 0.0025 & 15 & 8 & 0.2100 \\
\hline CONS & 11 & 3 & 0.0573 & 8 & 6 & 0.7905 \\
\hline Enterobacter & 9 & 4 & 0.2668 & 10 & 3 & 0.0922 \\
\hline Acinetobacter & 6 & 2 & 0.2890 & 5 & 3 & 0.7265 \\
\hline Serratia rubidaea & 3 & 0 & 0.2500 & 2 & 1 & 1.0000 \\
\hline Escherichia coli & 2 & 1 & 1.0000 & 3 & 0 & 0.2500 \\
\hline Pseudomonas & 2 & 0 & 0.5000 & 2 & 0 & 0.5000 \\
\hline Bacillus & 1 & 0 & 1.0000 & 1 & 0 & 1.0000 \\
\hline Staphylococcus aureus & 1 & 0 & 1.0000 & 1 & 0 & 1.0000 \\
\hline Non-hemolytic streptococcus & 0 & 1 & 1.0000 & 0 & 1 & 1.0000 \\
\hline Total & 54 & 15 & & 47 & 22 & \\
\hline
\end{tabular}

CONS Coagulase negative staphylococcus, EOS Early onset sepsis, LOS Late onset sepsis

Klebsiella, CONS and Enterobacter species were the most common organisms found in all groups; in both EOS and LOS, term and preterm babies. There was preponderance among EOS and preterm infants (Table 3); however, this observed difference was not statistically significant ( $p$-value>0.05) except for Klebsiella in EOS group ( $p$-value 0.0025 .

\section{Antibiotic susceptibility pattern}

\section{Among gram-negative organisms}

Within the beta-lactam antibiotics, Klebsiella demonstrated maximum susceptibility to Meropenem
(100\%), Imipenem (100\%) and Piperacillin-Tazobactam (Pip-Taz) (60\%) while showing high resistance to Ampicillin-Sulbactam (66.7\%) and Cefotaxime (90.5\%). Among non-beta-lactam antibiotics, Klebsiella showed maximum susceptibility to Colistin (88.8\%) and Tigecycline $(81.8 \%)$ while showing high resistance to Aminoglycosides and Quinolones.

Enterobacter species demonstrated high susceptibility to Meropenem (80\%), Tigecycline (85.7\%) and Colistin (87.5\%) while demonstrating high resistance to Cefotaxime (83.4\%).

Acinetobacter demonstrated good susceptibility to Ciprofloxacin (81.2\%), Colistin (80\%) and Tigecycline

Table 4 Antibiotics resistance among the major isolates

\begin{tabular}{|c|c|c|c|c|c|c|c|c|c|c|c|c|}
\hline \multirow[t]{2}{*}{ Antibiotic } & \multicolumn{2}{|c|}{$\begin{array}{l}\text { Klebsiella }(\mathrm{N}= \\
\text { 23) }\end{array}$} & \multicolumn{2}{|l|}{ CONS (14) } & \multicolumn{2}{|c|}{$\begin{array}{l}\text { Enterobacter }(N= \\
\text { 13) }\end{array}$} & \multicolumn{2}{|c|}{$\begin{array}{l}\text { Acinetobacter }(N= \\
\text { 8) }\end{array}$} & \multicolumn{2}{|c|}{$\begin{array}{l}\text { Escherichia coli }(N= \\
\text { 3) }\end{array}$} & \multicolumn{2}{|c|}{$\begin{array}{l}\text { Serratia rubidaea }(N= \\
\text { 3) }\end{array}$} \\
\hline & $R /(R+S)$ & $\mathrm{R} \%$ & $R /(R+S)$ & $\mathrm{R} \%$ & $R /(R+S)$ & $\mathrm{R} \%$ & $R /(R+S)$ & $\mathrm{R} \%$ & $R /(R+S)$ & $\mathrm{R} \%$ & $R /(R+S)$ & $\mathrm{R} \%$ \\
\hline \multicolumn{13}{|c|}{ Beta-lactam Antibiotics } \\
\hline Oxacillin & $6 / 6$ & 100 & $8 / 10$ & 80 & $3 / 3$ & 100 & $2 / 2$ & 100 & $1 / 1$ & 100 & $1 / 2$ & 50 \\
\hline Cefotaxime & $19 / 21$ & 90.5 & $4 / 6$ & 66.7 & $10 / 12$ & 83.4 & $6 / 7$ & 85.7 & $3 / 3$ & 100 & $1 / 3$ & 33.3 \\
\hline Meropenem & $0 / 18$ & 0 & $4 / 5$ & 80 & $2 / 10$ & 20 & $4 / 7$ & 57.1 & $2 / 3$ & 66.7 & $0 / 3$ & 0 \\
\hline Pip-Taz & $4 / 10$ & 40 & $1 / 2$ & 50 & $2 / 4$ & 50 & $3 / 6$ & 50 & $2 / 2$ & 100 & $1 / 3$ & 33.3 \\
\hline \multicolumn{13}{|c|}{ Non-beta-lactam Antibiotics } \\
\hline Amikacin & $12 / 21$ & 57 & $5 / 10$ & 50 & $0 / 1$ & 0 & $7 / 7$ & 100 & $3 / 3$ & 100 & $1 / 3$ & 33.3 \\
\hline Gentamicin & $15 / 20$ & 75 & $7 / 12$ & 58.3 & $5 / 13$ & 38.5 & $5 / 7$ & 71.4 & $2 / 3$ & 66.7 & $1 / 3$ & 33.3 \\
\hline Chloramphenicol & $13 / 20$ & 65 & $5 / 11$ & 45.5 & $8 / 13$ & 61.5 & $7 / 7$ & 100 & $3 / 3$ & 100 & $3 / 3$ & 100 \\
\hline Ciprofloxacin & $16 / 21$ & 76.2 & $8 / 10$ & 80 & $5 / 13$ & 38.5 & $3 / 16$ & 18.8 & $3 / 3$ & 100 & $1 / 3$ & 33.3 \\
\hline Ofloxacin & $13 / 18$ & 72.2 & $8 / 12$ & 66.7 & $1 / 12$ & 8.3 & $4 / 6$ & 66.7 & $3 / 3$ & 100 & $1 / 3$ & 33.3 \\
\hline Linezolid & - & - & $0 / 3$ & 0 & - & - & $1 / 1$ & 100 & - & - & $0 / 1$ & 0 \\
\hline Vancomycin & $1 / 1$ & 100 & $0 / 4$ & 0 & $1 / 1$ & 100 & - & - & - & - & $0 / 1$ & 0 \\
\hline Tigecycline & $2 / 11$ & 18.2 & - & - & $1 / 7$ & 14.3 & $2 / 6$ & 33.3 & $0 / 2$ & 0 & $0 / 1$ & 0 \\
\hline Colistin & $2 / 18$ & 11.2 & - & - & $1 / 8$ & 12.5 & $1 / 5$ & 20 & $0 / 3$ & 0 & $1 / 3$ & 33.3 \\
\hline
\end{tabular}

CONS Coagulase negative staphylococi, Pip-Taz Piperacillin-Tazobactam, $R$ Number of resistant isolates, R\% Percentage of resistant isolates, $S$ Number of susceptible isolates, [-] Not tested 
(66.7\%) while it was highly resistant to Amikacin (100\%), Chloramphenicol (100\%) and Cefotaxime (85.7\%).

Escherichia coli demonstrated marked resistance to commonly used antibiotics, showing susceptibility only to reserved antibiotics like Tigecycline and Colistin (Table 4).

\section{Among gram-positive organisms}

CONS, Methicillin-resistant Staphylococcus aureus (MRSA) and Non-hemolytic Streptococcus were the most common gram-positive organisms associated with neonatal sepsis in our study. The majority of CONS were resistant to commonly used antibiotics (Table 4). A single case of MRSA isolated in our study showed susceptibility to Amikacin, Gentamicin, Ofloxacin, Pip-Taz, and Linezolid. One case of Non-hemolytic Streptococcus isolate showed susceptibility to Amoxicillin, Gentamicin and Chloramphenicol, but surprisingly resistance to Cefotaxime and Ofloxacin.

\section{Status of global antibiotic resistance}

Overall resistance to individual antibiotics among gram-positive and gram-negative isolates is summarized in Table 5. It shows alarming rates of resistance to

Table 5 Overall status of antibiotic resistance among the grampositive and gram-negative isolates

\begin{tabular}{|c|c|c|c|c|}
\hline \multirow[t]{2}{*}{ Antibiotics tested } & \multicolumn{2}{|c|}{ Gram-negative } & \multicolumn{2}{|c|}{ Gram-positive } \\
\hline & $\mathrm{R}$ & $\mathrm{R} \%$ & $\mathrm{R}$ & $\mathrm{R} \%$ \\
\hline \multicolumn{5}{|l|}{ Beta-lactam antibiotics } \\
\hline Amoxicillin & 38 & 100.0 & 7 & 87.5 \\
\hline Oxacillin & 11 & 91.7 & 8 & 100.0 \\
\hline Cefotaxime & 33 & 80.5 & 5 & 62.5 \\
\hline Meropenem & 4 & 11.8 & 2 & 40.0 \\
\hline Piperacillin-Tazobactam & 9 & 47.4 & 1 & 33.3 \\
\hline Ampicillin-Sulbactam & 2 & 66.7 & 1 & 100.0 \\
\hline Imipenem & 1 & 8.3 & - & - \\
\hline Aztreonam & 1 & 50.0 & - & - \\
\hline \multicolumn{5}{|l|}{ Non-beta-lactam antibiotics } \\
\hline Amikacin & 21 & 50.0 & 5 & 45.5 \\
\hline Gentamicin & 24 & 60.0 & 7 & 50.0 \\
\hline Tobramycin & 1 & 50.0 & 1 & 100.0 \\
\hline Chloramphenicol & 29 & 70.7 & 6 & 46.2 \\
\hline Ciprofloxacin & 25 & 62.5 & 8 & 61.5 \\
\hline Ofloxacin & 18 & 47.4 & 9 & 64.3 \\
\hline Linezolid & - & - & 0 & 0.0 \\
\hline Vancomycin & 2 & 66.7 & 0 & 0.0 \\
\hline Tigecycline & 3 & 14.3 & - & - \\
\hline Cotrimoxazole & 1 & 33.3 & - & - \\
\hline Colistin & 6 & 17.6 & 3 & 100.0 \\
\hline Teicoplanin & 1 & 50.0 & - & 87.5 \\
\hline
\end{tabular}

$R$ Number of resistant isolates, $R \%$ Percentage of resistant isolates commonly used antibiotics. The resistance to the current first and second line empirical therapy was 72 and $65 \%$ respectively.

\section{Discussion}

Neonatal sepsis is considered the leading cause of infant mortality and morbidity in the NICU. Two previous studies conducted in neonatal nurseries from Patan Hospital during the period of 2000-2005 and 2006-2007 showed culture positivity of 13.7 and $19.56 \%$ respectively $[7,8]$. However, our study, which is first of its kind to be conducted in NICU of the same institute, showed culture positivity of neonatal sepsis to be $20.7 \%$. In contrast, studies conducted at KIST Medical College and Manipal College of Medical Sciences, Nepal showed culture positivity to be 48 and $44.9 \%$ respectively $[9,10]$. Variations in culture positivity rate of neonatal sepsis in different studies seem to arise from differences in culture-techniques and study designs.

The majority of culture positive sepsis was EOS and among preterm and low birth weight neonates, similar to the study findings of Kathmandu University Hospital (KUH), Dhulikhel, Nepal [11].

The most common clinical manifestation of neonatal sepsis in our study was respiratory distress (79\%). Similar findings were noted in studies from KIST Medical College, Nepal (54\%) and Beni Suef University Hospital, Egypt $(36 \%)[9,12]$. At our center, we take CRP as a biomarker of sepsis and its serial decline is taken as laboratory evidence of improvement. In the initial screening test, the majority had raised CRP (75\%) and low platelet count $(84 \%)$ whereas low ANC was seen only in $20 \%$ of the cases.

The majority of the isolates were gram-negative, similar to the findings of Shrestha $\mathrm{S}$ et al. and that of investigators of the Delhi Neonatal Infection Study (DeNIS) Collaboration [11, 13]. In contrast, Peterside O et al. in Nigeria and Sharma P et al. in India showed a preponderance of gram-positive organisms of which Staphylococcus aureus was the most prevalent [14]. One reason for this variation could be due to the difference in adherence to infection prevention and control measures.

Klebsiella species were the most frequent causative organisms of neonatal sepsis in our study, a similar finding to that of Shrestha $S$ et al. [11]. In contrast, previous studies conducted at the same institute in the neonatal nurseries showed CONS as a major isolate $[7,8]$. The variation in the major isolate could be due to differences in study setting, study population and adherence to hand hygiene practices. Similar CONS predominance was reported by Mohamadi $\mathrm{P}$ et al. [15]. The same bacterial 
isolates were attributed to neonatal sepsis among the EOS and LOS groups, in agreement with Shrestha S et al's and Singh HK et al's [11, 16] findings. In contrast, studies by Mahmood A et al. and Ingale HD et al. demonstrated Klebsiella in EOS and Staphylococcus in LOS as common causative organisms $[17,18]$. Wu JH et al. in Taiwan, found GBS and Methicillin resistant-CONS to be the most frequent cause among EOS and LOS respectively [19].

Our study shows the majority of causative organisms have developed resistance to these frequently used antibiotics; Amoxicillin, Cefotaxime and Oxacillin from the beta-lactam group. This finding is consistent with studies done in neonatal nurseries of the same institute and NICUs in other parts of Nepal and Pakistan [7, 8, 11, 12, 17]. Both gram-positive and gram-negative organisms showed high susceptibility to Carbapenems, a similar finding to other studies conducted both inside and outside Nepal [11, 12, 17]. Similarly, gram-negative organisms showed high susceptibility to Colistin, which is consistent with the findings of Jessan Bonny et al. [20].

Vancomycin and Linezolid showed high (100\%) susceptibility towards gram-positive isolates, similar to the finding's of Mullah SA et al. and Singh HK $[16,21]$. Amikacin showed moderate susceptibility against both gram-positive and negatives. Among second-line antibiotics, Chloramphenicol had low susceptibility (29.3\%) against gram-negatives compared to gram-positives (53.8\%). Whereas Ofloxacin had moderate susceptibility (52.6\%) to gram-negatives.

Klebsiella and Enterobacter, the main gram-negative isolates showed maximum susceptibility to Carbapenems, followed by Colistin and Tigecycline respectively. Such high susceptibility toward Carbapenem was also documented by Sheth KV et and Yusuf D et al. [22, 23].

Acinetobacter demonstrated good susceptibility to Ciprofloxacin, Colistin, and Tigecycline. Although our study showed high susceptibility towards Ciprofloxacin various other studies reported low susceptibility [11, 24].

Escherichia coli showed high resistance to the first and second line empirical antibiotics used commonly in our institution, only demonstrating susceptibility towards Colistin and Tigecycline. In contrast to this, Singh HK et al. and Sheth KV et al. showed good susceptibility towards commonly used antibiotics [16, 24]. This indicates the emergence of highly resistant strains of Escherichia coli in our setting.

CONS has been reported in various studies as the most common cause of neonatal sepsis in NICUs $[19,22]$. The second commonest cause of neonatal sepsis in our study, CONS showed low susceptibility to Penicillin, third generation Cephalosporin and intermediate to Aminoglycosides and high susceptibility to Linezolid and Vancomycin. Sarangi KK et al. and Dalal $\mathrm{P}$ et al. also demonstrated high Vancomycin susceptibility in their studies $[25,26]$.

GBS, the most common cause of EOS in high-income countries, has a low reported incidence in low and middle-income countries [27]. Such low incidence of GBS sepsis in EONS is consistent with our findings. Possible reasons for this could include overuse of antibiotics during the antenatal period or substandard culture techniques and microbiological methods [28, 29]. At our institution, intravenous Crystalline Penicillin is given for mothers with PROM and intravenous Metronidazole and Gentamicin along with Crystalline Penicillin for mothers with chorioamnionitis as intrapartum antibiotic prophylaxis. Over diagnosis of PROM and chorioamnionitis and subsequent antibiotic treatment could be the reason for low yield of GBS at our institution.

In our study, the overall mortality rate in culture positive sepsis was $15.94 \%$, which is consistent with the studies from Egypt and India [12, 30, 18]. The highest mortality was seen in the Enterobacter and Klebsiella sepsis group. Though the highest case fatality rate was observed with Pseudomonas sepsis, its limited yield hinders the generalization of this result. A combination of Pip-Taz and Ofloxacin as first line empirical therapy, or Vancomycin and Meropenem as second line would reduce the overall resistance by 22 and $46 \%$ respectively. The current first line therapy covers only $28 \%$ of the isolates whereas the proposed first line therapy with Pip-taz and Ofloxacin would successfully cover $50 \%$ of the isolates.

The emergence of MDR bacteria presents a great challenge to the management of neonatal sepsis, causing significant morbidity and mortality. The prevalence of neonatal sepsis due to MDR strains in our study was 73.91\%. MDR among gram-negatives and gram-positives was 80.76 and $52.94 \%$ respectively in our study, which is in agreement with the findings of DeNIS Collaboration from India and Labi AK et al. from Ghana [13, 6].

The retrospective design of our study, together with its single centered, small study population and limited yield of some pathogens were all limitations in our study. Hence, large-scale, multi-center prospective studies are needed to validate our findings.

\section{Conclusions}

Our study revealed gram-negative isolates as the predominant pathogens in both EOS and LOS groups. Both gram-positive and gram-negative isolates showed high resistance to commonly used antibiotics. Significant proportions of them were MDR strains. Such high antibiotic resistance is associated with significant neonatal morbidity and mortality. Based on our findings, a combination of Pip-Taz and Ofloxacin as first line therapy, or a 
combination of Vancomycin and Meropenem as second line would be the appropriate empirical therapy. However, the use of the broad-spectrum antibiotics as empirical therapy could be detrimental in the long run and hence they should be used judiciously and modified to narrow spectrum antibiotics, as guided by the culture and susceptibility report at the earliest opportunity. The best prevention of neonatal sepsis comprises of early recognition of high-risk infants and strict infection control practices, such as safe delivery, hand hygiene, avoidance of unnecessary invasive procedures and restricted entry to the NICU. To prevent the emergence of drug resistance, comprehensive approach consisting of evaluation of antibiotic consumption, improvement in laboratory techniques, rational use of empirical therapy and de-escalation/discontinuation of therapy when suitable along with continuous surveillance and monitoring of local epidemiology is needed. Use of synbiotics in a recent trial in India has shown promising results in prevention of neonatal sepsis in developing countries [31]. Use of Matrix assisted laser deserption ionization-time of flight mass spectrometry (MALDI-TOF MS), a nobel technique for the rapid identification of isolates and their antimicrobial susceptibility is yet to be explored in low-income countries like Nepal.

\begin{abstract}
Abbreviations
ANC: Absolute neutrophil count; CONS: Coagulase-negative Staphylococci; CRP: C-reactive protein; EOS: Early-onset sepsis; GBS: Group B Streptococcus; LOS: Late-onset Sepsis; MDR: Multidrug-resistant; MRSA: Methicillin-resistant Staphylococcus aureus; NICU: Neonatal intensive care unit; PIP-

TAZ: Piperacillin-Tazobactam; PROM: Prolonged rupture of membrane
\end{abstract}

\section{Acknowledgements}

We are grateful to Dr. Katrina Butterworth MD, Professor of General Practice and Dr. Darlene R. House, MD, MS, Assistant Professor of Clinical Emergency Medicine for proofreading our manuscript.

\section{Ethical approval and consent to participate}

Ethical approval was obtained from Institutional Review Committee (IRC) of Patan Academy of Health Sciences (PAHS) $(\mathrm{drs} 1,710,131,137)$ before the study was conducted. Written consent from the caregiver of the neonates could not be obtained due to retrospective nature of the study. However, all the patient related information was anonymized.

\section{Funding}

This work did not receive any funding from any source.

\section{Availability of data and materials}

The dataset generated or analyzed during this study can be made available to interested researcher by the authors of this article on reasonable request.

\section{Authors' contributions}

BP, TK and PB conceived and designed the study, collected and analyzed the data and drafted the manuscript. SJ and GS revised the manuscript for critically important intellectual content. BP, TK and PB finalized the manuscript. All authors read and approved the final manuscript.

\section{Consent for publication}

Not applicable.

\section{Competing interests}

The authors declare they have no competing interests.

\section{Publisher's Note}

Springer Nature remains neutral with regard to jurisdictional claims in published maps and institutional affiliations.

\section{Author details}

'Department of Pediatrics, Patan Academy of Health Sciences, Lagankhel, PO Box 26500, Lalitpur, Nepal. ${ }^{2}$ School of Medicine, Patan Academy of Health Sciences, Lagankhel, Lalitpur, Nepal. ${ }^{3}$ School of Health and Allied Sciences, Pokhara University, Lekhnath-12, Kaski, Nepal.

Received: 23 January 2018 Accepted: 11 June 2018

Published online: 27 June 2018

\section{References}

1. United Nations Inter-agency Group for Child Mortality Estimation (UNIGME). Levels and trends in child mortality report 2017. New York: United Nations Children's Fund; 2017. 36p. Available from: https://www. unicef.org/publications/files/Child_Mortality_Report_2017.pdf. Accessed 1 Dec 2017.

2. Ministry of Health, Nepal; New ERA; ICF. Nepal demographic and health survey 2016. Kathmandu, Nepal: Ministry of Health, Nepal; 2017 Nov. 411 p. Available from: https://www.dhsprogram.com/pubs/pdf/FR336/FR336.pdf. Accessed 1 Dec 2017.

3. Winn WC, Allen SD, Janda WN, Koneman E, Procop G, Schreckenberger P, Woods $G$. Koneman's color atlas and textbook of diagnostic microbiology. 6th ed. Philadelphia: Lippincott; 2006.

4. Clinical and Laboratory Standards Institute (CLSI). Performance standards for antimicrobial susceptibility testing; twenty-fourth informational supplement. Wayne (PA): Clinical and Laboratory Standard Institute; 2014 Jan. Report No.: CLSI document M 100-S24.

5. National Neonatology Forum NNPD Network, India. National neonatalperinatal database report 2002-2003. New Delhi: National Neonatology Forum NNPD Network, India; 2005 Jan. 70p. Available from: http://www. newbornwhocc.org/pdf/nnpd_report_2002-03.PDF. Accessed 4 Dec 2017.

6. Labi AK, Obeng-Nkrumah N, Bjerrum S, Enweronu-Laryea C, Newman MJ. Neonatal bloodstream infections in a Ghanaian tertiary hospital: are the current antibiotic recommendations adequate? BMC Infect Dis. 2016 16:598. Available from: https://doi.org/10.1186/s12879-016-1913-4. Accessed 4 Dec 2017.

7. Shrestha S; Adhikari N; Shakya D; Manandhar L, Chand A. Bacteriological profile of neonatal blood cultures at Patan hospital. J Nepal Paediatr Soc. 2007 26(1):1-4. Available from: https://www.popline.org/node/198598. Accessed 5 Dec 2017.

8. Shrestha S, Adhikari N, Rai BK, Shreepaili A. Antibiotic resistance pattern of bacterial isolates in neonatal care unit. J Nepal Med Assoc. 201049 (180): 277-281. Available from: http://www.jnma.com.np/jnma/index.php/jnma/ article/view/54/416. Accessed 5 Dec 2017

9. Lakhey A, Shakya H. Role of sepsis screening in early diagnosis of neonatal sepsis. J Pathol Nepal. 2017;7(1):1103-1110. Available from: https://doi.org/ 10.3126/jpn.v7i1.16944. Accessed 6 Dec 2017.

10. Shrestha NJ, Subedi KU, Rai GK. Bacteriological profile of neonatal sepsis: a hospital based study. J Nepal Paediatr Soc. 2011:31 (1):1-5. Available from: https://doi.org/10.3126/jnps.v3111.4158. Accessed 9 Dec 2017.

11. Shrestha S, Shrestha NC, Dongol Singh S, Shrestha RPB, Kayestha S, Shrestha M. Bacterial isolates and its antibiotic susceptibility pattern in NICU. Kathmandu Univ Med J. 2013:41(1):66-70. Available from: http://www.kumj. com.np/issue/41/66-70.pdf. Accessed 9 Dec 2017.

12. Fahmey SS. Early-onset sepsis in a neonatal intensive care unit in Beni Suef, Egypt: bacterial isolates and antibiotic resistance pattern. Kor J Pediatr 2013; 56(8):332-337. Available from: https://doi.org/10.3345/kjp.2013.56.8.332. Accessed 12 Dec 2017.

13. Investigators of the Delhi Neonatal Infection Study (DeNIS) collaboration. Characterisation and antimicrobial resistance of sepsis pathogens in neonates born in tertiary care centres in Delhi, India: a cohort study. Lancet Glob Health. 2016; e752-e760. Available from: https://doi.org/10.1016/ S2214-109X(16)30148-6. Accessed 16 Feb 2018.

14. Sharma P, Kaur P, Aggarwal A. Staphylococcus aureus- the predominant pathogen in the neonatal ICU of a tertiary care hospital in Amritsar, India. J Clin Diagn Res. 2013;7(1): 66-69. Available from: https://doi.org/10.7860/ JCDR/2012/4913.2672. Accessed 14 Dec 2017. 
15. Mohammadi P, Kalantar E, Bahmani N, Fatemi A, Naseri N, Ghotbi N, Naseri $\mathrm{MH}$. Neonatal bacteriemia isolates and their antibiotic resistance pattern in neonatal intensive care unit (NICU) at Beasat hospital, Sanandaj, Iran. Acta Medica Iranica. 2014 52(5):337-40. Available from: http://acta.tums.ac.ir/index.php/acta/article/download/4624/4414 Accessed 14 Dec 2017

16. Singh HK, Sharja P, Onkar K. Bacteriological profile of neonatal sepsis in neonatal intensive care unit (NICU) in a tertiary care hospital: prevalent bugs and their susceptibility patterns. Eur J Pharmaceutical Med Res 2016; 3(3):241-245. Available from: http://www.ejpmr.com/admin/assets/ article issue/1457056566.pdf. Accessed 14 Dec 2017.

17. Mahmood A, Karamat KA, Butt T. Neonatal sepsis: high antibiotic resistance of the bacterial pathogen in a neonatal intensive care unit in Karachi. J Pak Med Assoc.200252(8):348-350. Available from: http://www.jpma.org.pk/full_ article text.php?article id=2358. Accessed 15 Dec 2017.

18. Ingale HD, Kongre VA, Bharadwaj RS. A study of infections in neonatal intensive care unit at a tertiary care hospital. Int J Contemp Pediatr. 20174(4):1349-1356. Available from: https://doi.org/10.18203/2349-3291. ijcp20172664. Accessed 16 Dec 2017.

19. Wu JH, Chen CY, Tsao PN, Hsieh WS, Chou HC. Neonatal sepsis: a 6-year analysis in a neonatal care unit in Taiwan. Pediatr Neonatol. 200950(3):8895. Available from: https://doi.org/10.1016/S1875-9572(09)60042-5. Accessed 16 Dec 2017.

20. Jasani B, Kannan S, Nanavati R, Gogtay NJ, Thatte U. An audit of colistin use in neonatal sepsis from a tertiary care centre of a resource-limited country. Indian J Med Res. 2016144(3):433-439. Available from: https://doi.org/10. 4103/0971-5916.198682. Accessed 18 Dec 2017.

21. Mulla SA, Revdiwala SB. Neonatal High antibiotic resistance of the bacterial pathogens in a neonatal intensive care unit of a tertiary Care hospital. J Clin Neonatol. 2012;1(2):72-75. Available from: https://doi.org/10.4103/2249-4847. 96753. Accessed 18 Dec 2017.

22. Sheth KV, Patel TK, Tripathi CB. Antibiotic sensitivity pattern in neonatal intensive care unit of a tertiary care hospital of India. Asian J Pharm Clin Res. 2012 5(3):46-50. Available from: http://www.ajpcr.com/Vol5lssue3/965. pdf. Accessed 18 Dec 2017.

23. Yusef D, Shalakhti T, Awad S, Algharaibeh H, Khasawneh W. Clinical characteristics and epidemiology of sepsis in the neonatal intensive care unit in the era of multi-drug resistant organisms: a retrospective review. Pediatr Neonatol. 2017 June;59(1):35-41. Available from: https://doi.org/10. 1016/j.pedneo.2017.06.001. Accessed 18 Dec 2017.

24. Shaw CK, Shaw P, Thapalial A. Neonatal sepsis bacterial isolates and antibiotic susceptibility patterns at a NICU in a tertiary care hospital in western Nepal: A retrospective analysis. Kathmandu Univ Med J. 2007;5(18): 153-160. Available from: http://www.kumj.com.np/issue/18/153-160.pdf. Accessed 20 Dec 2017

25. Sarangi KK, Pattnaik D, Mishra SN, Nayak MK, Jena J. Bacteriological profile and antibiogram of blood culture isolates done by automated culture and sensitivity method in a neonatal intensive care unit in a tertiary care hospital in Odisha, India: Int J. Adv Med. 2015:2(4):387-92. Available from: https://doi.org/10.18203/2349-3933.ijam20151015. Accessed 20 Dec 2017

26. Dalal P, Gathwala G, Gupta M, Singh J. Bacteriological profile and antimicrobial sensitivity pattern in neonatal sepsis: a study from North India. Int J Res Med Sci. 2017:5(4):1541-1545. Available from: https://doi.org/10. 18203/2320-6012.ijrms20171261. Accessed 20 Dec 2017.

27. Fuchs A, Bielici J, Mathur S, Sharland M, van den Anker JN. Antibiotic use for sepsis in neonates and children: 2016 evidence update. WHOReviews; 2016. 25 p. Available from: http://www.who.int/selection_ medicines/committees/expert/21/applications/s6 paed antibiotics appendix4_sepsis.pdf. Accessed 21 Dec 2017.

28. Moore MR, Schrag SJ, Schuchat A. Effects of intrapartum antimicrobial prophylaxis for prevention of group B streptococcal disease on the incidence and ecology of early-onset neonatal sepsis. Lancet Infect Dis. 20033(4):201-13. Available from: http:// doi.org/10.1016/S14733099(03)00577-2. Accessed 21 Dec 2017

29. Stoll BJ, Schuchat A. Maternal carriage of group B streptococci in developing countries. Pediatr Infect Dis J. 1998;17:499-503. Available from: http://journals.Iww.com/pidj/Abstract/1998/06000/Maternal_carriage_of_ group_B_streptococci_in.13.aspx. Accessed 22 Dec 2017.

30. Mohsen L, Ramy N, Saied D, Akmal D, Salama N, Abdel Haleim MM, Aly $\mathrm{H}$. Emerging antimicrobial resistance in early and late-onset neonatal sepsis. Antimicrob Resist Infect Control. 2017;6(63):1-9. Available from: http:// doi.org/10.1186/s13756-017-0225-9. Accessed 22 Dec 2017.

31. Panigrahi P, Parida S, Nanda NC, Satpathy R, Pradhan L, Chandel DS, Baccaglini L, Mohapatra A, Mohapatra SS, Misra PR, Chaudhry R, Chen HH, Johnson JA, Morris JG, Paneth N, Gewolb IH. A randomized synbiotic trial to prevent sepsis among infants in rural India. Nature 2017:548(7668):407-412. Available from: https://doi.org/10.1038/nature23480. Accessed 2018 Feb 15.

\section{Ready to submit your research? Choose BMC and benefit from:}

- fast, convenient online submission

- thorough peer review by experienced researchers in your field

- rapid publication on acceptance

- support for research data, including large and complex data types

- gold Open Access which fosters wider collaboration and increased citations

- maximum visibility for your research: over $100 \mathrm{M}$ website views per year

At BMC, research is always in progress.

Learn more biomedcentral.com/submissions 